\title{
Reflexive Europe and the Era of Late Modernity ${ }^{1}$
}

\author{
Zoltán Grünhut \\ Centre for Economic and Regional Studies \\ Toth Kalman 4, \\ Budapest 1097, Hungary \\ E-mail: grunhut@rkk.hu
}

\begin{abstract}
The paper proposes a conceptualization on 'Europe' using late modernity as a social grand theory for background. It builds primarily on Giddens' modernization argument, while the paper also invokes an intentionality framework in order to better describe the interrelation between individual emancipation and institutional reflexivity. 'Europe' as entity is normatively (re)theorized through this lens, i.e. how it can contribute to the subjects' self-liberating agency. The paper focuses with particular attention on institutional shifts in four sectors-education, labor, science, and art.
\end{abstract}

Keywords: Europe, late modernity, self-emancipation, institutional reflexivity

\section{Introduction}

Although there is a growing literature about different conceptualizations on 'Europe', which sources are reflecting on various grand narratives as backgrounds, it may not be an exaggeration to claim that the scholars who have proposed significant theoretical novelties in this scope are not from the field of European studies (see, e.g., Balibar, 2003; Beck \& Grande, 2007; Delanty, 2003; 2016; Delanty \& Rumford, 2005; Habermas, 2009). Therefore, it is more common to reinterpret general social theories through the framework of the so-called 'European project' than to embed certain midrange concepts of European studies into abstract grand narratives. Undoubtedly, both attempts would be important to better understand the socio-political and socio-cultural processes inside and

1 The paper is dedicated to Yelda Karadağ in appreciation of her inspiring thoughts. Project no. PD124706 ('The Normative Actorness of the European Union') has been implemented with the support provided from the National Research, Development and Innovation Fund of Hungary, financed under the PD17 funding scheme. 
outside 'Europe'; however, scholars of European studies seem to be reluctant to link their particular explanations to overarching social theories.

This paper aims to contribute to the conceptualization of 'Europe' through abstract theorization. It takes Anthony Giddens' theorem on modernization as a grand narrative, and tries to understand the evolution of institutional shifts through this theoretical lens. The approach distinguishes between three levels of intentionality in the social structure. Two of these belong to the micro (individual) level: pre-intentionality is about the subject's routinized ideas and praxes make up the pillars of one's identity, while intentionality is the purposefully gained reflexive and critical actorness supposed to correct/update individual routines if they fail to be reliable in intersubjective (social) and subjective (object- or nature-related) interactions. Compared to these micro-dimensions, post-intentionality evolves at the macro (collective) level as it is about the institutional shifts (reflections) facilitated by the subjects' actorness. This is how agents and structures are shaping and reshaping each other; if the formers are reflexive, then the latter will evolve along the same way, however if individuals uncritically stick themselves to institutionalized references in order to stabilize their routines, then actorness will be overly framed.

Through this framework the project of 'Europe' could be re-conceptualized under the overarching grand narrative of late modernity. This theoretical effort helps to understand how the European entity as a reflexive institutional constellation could contribute to the individual subjects' self-emancipation. Four sectors, the fields of education, labor, science and art, will be particularly addressed below in order to shed light on the reflexively and critically initiated institutional reflections of Europe.

\section{Giddens' theorem on modernization}

Anthony Giddens started his series of theorization about the process of modernization in 1990 with his book titled The Consequences of Modernity. One of his main arguments is that modernization is not a linear process; it has different phases, yet the tendencies could be shifted from one form to another, and then back again, even though some fundamental changes are slowly progressing. Therefore, the various stages of modernization are not fully unfolded or exceeded, but they are more in an interrelation that generates 
paradox social constellations (Giddens, 1990). Accordingly, Giddens does not accept the term post-modernity; he prefers to call our days as the era of late modernity. In this period, the new social experiences about modernization are mostly due to the interconnectedness of globalization and localization, i.e., because of a growing tension between abstraction of institutions and how the actors could deal with this universalization in their interactions (Beck, Giddens $\&$ Lash, 1994). The radicalizing process of late modernity, which facilitates previously unknown pressures on subjects, is that the "hard" structures are becoming fluid, and individual routines (ideas and praxes) based on these once so stable institutional references are turning to be dysfunctional, inadequate, and non-applicable.

In the pre-modern era it was mostly religious traditions that served as structural pillars, imposing hierarchical stratification, superior-inferior statuses, onedimensional cognitive-normative ideational substances, and tightly constrained praxes on subjects. Certain elites as powerful agents with the function of "gate-keepers" took care of the traditional semantics which, as references, were legitimizing sources to this social constellation (Giddens, 1995). Then after the Enlightenment and the emergence of the Westphalian world order, national ethos pushed back the relevancy of religious traditions. The unified state and its expanding bureaucracy, as well as public services such as compulsory education based on national language, promoting national culture and history, or home front defense socializing people in the 'we' (in-group)-'they' (out-group) dichotomy opened up a new era in modernization. Secularism, rationalization, and market logics (Weber), as well as the extension of (partly imagined) social (national) unitedness (Anderson) from community (Gemeinschaft) to society (Gesellschaft) (Tönnies), or from mechanical to organic solidarity (Durkheim), i.e., a growing functional (Parsons, Luhmann) and systemic differentiation (Bourdieu) of societies undermined the roles of traditional "gate-keepers" and promoted "experts" into their statuses (Giddens, 1995). In this post-traditional phase of modernization, "knowledge-producer" experts proclaimed that only decontextualized, formal, falsifiable and universal ideas could be accepted as rational and objective (or scientific), the understanding of which questioned both the traditional logics and the structural constellations (hierarchies, constraints, beliefs, praxes, etc.) based on these semantics. This shift contributed to the subjects' reflexivity and critical agency, thus it paved the way for growing freedoms, autonomies and pluralism both respective to collective and individual constitutions of identity (Giddens, 1991). 
In line with this argument, Giddens (1990) claims that the history of modernization is basically the progression/regression of individual reflexivity, which is unfolding in a historically considered spatio-temporal perspective, yet not like a continuous, linear trend, and absolutely not in an unconstrained sense, as certain disciplinary mechanisms very much frame it. What is new in late modernity compared to the classic era is that contingencies are pervading as the interconnectedness of globalization and localization (or the planetary interrelatedness of flows, among them limitless and boundless streaming of people, products, services, information, digitalization, as well as various threats and hazards, e.g., ecology crisis, terrorism, extremism, state-failings, international crimes, etc.) facilitates institutional abstractions, so particular cultural references cannot be unequivocally grasped and applied in diverse subjective and intersubjective interactions any longer (Beck, Giddens \& Lash, 1994). Thus, there is a growing pressure on individuals to be reflexive, to critically review their internalized patterns, yet they are left alone to find out by themselves what to do with their dysfunctional, inadequate, and non-applicable ideational substances and praxes as there are no alternative references to follow.

Two separable, but strongly interlinked abstraction processes should be mentioned (Beck, 1992; 1998). At first there are relevant uncertainties because of the tendency of multiplying interdependencies between actors and abstract entities. Due to the globalized and extreme division of labor, accessibility to services and goods depends on extensive and multi-layered production-chains of networking agents. This constellation triggers vulnerabilities not just because self-sufficiency is seriously limited in this context, but also due to the growing number of depersonalized, technologized interactions. In more and more cases intersubjective interactions are replaced by subjective ones, where people need to deal with either anonymous partners or with automatized/robotized objects. At the same time, individuals are overwhelmed by all kinds of information; they are unwittingly and unintentionally plugged in to the global stream of news and data shared and interpreted by a diverse pool of "spokespeople". Subjects cannot fully comprehend the multilevel web of different agents and their objectives, functions, authorities, policies, tasks, and responsibilities in the globalized arenas. They experience that somehow their "inhabited world" is expanding and shrinking simultaneously; while the flows radically widen local contexts, without common references diverse individual approaches on how to reflect on these contents/situations undermine the sense of belonging to a certain community. Therefore, globalization/localization have dual impacts; both bringing closer (connect by flows) and tearing apart (disconnect by abstractions). Abstractions, 
thus, shake local structures and therefore also question the reference value of particular cultures (Beck, Giddens \& Lash, 1994).

So, while there are uncertainties that trace back to structural trends of depersonalization, technologization, evolution of digital and organizational mega-systems, and globalization of various flows on the one hand, these contingencies also have serious impacts on social statuses, roles, positions, relations, and interactions on the other hand, since local cultures are losing their structural fundaments (Beck, 1999). As a consequence, traditional semantics are being continuously deconstructed through heated public-political debates (narratively) and by unconventional actions (performatively). The once normbreaking perceptions about Man and Woman are diffusing (Giddens, 1992). Patriarchal structures are no longer defendable as their legitimizing semantics are unveiled to be male chauvinist and sexist. The traditional dominance of men is under heavy pressure as narratives and performances in the fields of arts, literature, sciences, etc. undermine patriarchal logics, while these social-cultural arguments are able to mobilize masses through social media and civil movements. The "othering" of women through patriarchal comparisons and by oversimplified ideas (such as that women are physically weaker, more sensitive, more affective, more caring, more romantic, less competitive, less autonomous, more aestheticminded, etc.) is a traditional semantic that cannot keep being a reference any longer. Due to the delegitimization of these perceptions and interpretations more and more women are liberated (by themselves) from their reified statuses. This process has fundamental impacts on women's lifestyles from relationships (roles in family, status of marriage, courtships and friendships), through education and career (studies, positions, employment, entrepreneurship), to consumption and public-political engagement (Beck \& Beck-Gersheim, 1995).

All these changes de- and reconstruct differently the status of loving relationships. Neither the traditional narratives (romantic bond) nor the legal interpretation (marriage as a pact) can stand for itself as a strong reference in late modernity (Giddens, 1992). Instead, the aspects of intimacy, togetherness, equality, honesty, bond of communion, mutuality, respect, giving freedom and space, providing a supportive and inspirational atmosphere to each other are becoming essential features of a courtship/loveship. The sexual orientation of the parties does not matter, the traditional model is not universal anymore. The emphasis is on the quality of the relationship, if it can safeguard an intimate connectedness for the couple to live a peaceful life in an era full of contingencies (Beck \& BeckGersheim, 2002). Therefore, break-ups are not considered as failures as long 
as the once satisfying relationships are no longer able to function according to the aforementioned features. On the contrary, to cut short these unhappy partnerships is a reflexive action contributing to one's emancipation. In line with these trends, the concept of marriage is changing as well. Couples are together for years or decades without being married; frequently they are not keeping a common household or living in the same area. Long-distance relations are thriving, more commonly between people with very different national and cultural backgrounds. It is more and more a tendency that not just men but also women-irrespective of age-enjoy the autonomy from social pressures to be single, or to have a relationship without being married. The connotation of divorcement is also different than it used to be. If a loving relation is not working then its legal status cannot hold it together either, so the procedure of getting divorced is demanded to be faster and easier. In line with this, contracts about separated incomes, bank accounts, and properties are becoming usual features of a marriage.

Of course, family as a basic social unit is perceived through a new lens as well. The traditional model of father, mother and kid(s) does not have a reference value any more (Giddens, 1992). On the one hand, homosexual couples in more and more countries have the same rights as heterosexual ones (to marry, to adopt, to have joint loans and credits, to enjoy family-related social benefits and subsidies, etc.), while on the other hand, single-parent families are widely accepted and respected, both socially and institutionally. The roles of family members are also changing rapidly. Neither based on gender nor due to traditional family functionality there should not be a distinction between "breadwinning" and "childrearing-housekeeping" tasks (Beck \& Beck-Gersheim, 2002). Although it is an inherent mechanism of every relationship that the parties are identifying themselves with certain roles, these are not socially-culturally pressured in late modernity, therefore the flexibility of being reflexively adaptive to changing circumstances is expected from the couples. The relevancy of "strong ties", i.e., intensive informal relations between different generations of an extended family (for instance, to have common household, to ask for daily favors, to share certain costs, etc.) are decreasing; nuclear families are more relying on formal relations with various organizations in their everyday issues.

The above-described contingencies grouped according to two interrelated dimensions of abstraction processes (depersonalization, technologization, evolution of digital and organizational mega-systems, and globalization of flow on the one hand, and radical changes to social roles, relationships, marriage, 
family, sexuality and body on the other) make individuals responsible to constitute their identities, to construct their ideas, and to develop routinized praxes by themselves without clear references (Giddens, 1990). These abstraction processes undermine the local structures, and therefore shake the last bastions of locally rooted (particular) traditional logics and semantics. Due to these shifts individuals have to rely more on their reflexive and critical agencies. Yet, without references both subjective and intersubjective interactions are pervaded with uncertainties. People, thus, need to perceive and manage these risks continuously in order to keep their actorness alive (Beck, Giddens \& Lash, 1994). Giddens (1991) argues that in late modernity one of the core intentions of subjects is to maintain their ontological security. In a pre-intentional level these efforts are striving for the constitution of reliable ideational substances and the application of adequate routine praxes. Subjects, thus, aim to "colonize" their future, they try to control it, make it foreseeable and pre-planned. Ontological security is based on four dimensions of these pre-intentional ideas and praxes: (1) perceptions and interpretations about existence- the constellation of the self and the "world out there"; (2) individual understandings about the meaning of life and its limits; (3) the both narratively and performatively constituted "project of life" as a multiphased subjective journey (from past, through present, to future); and finally (4) one's ever redesigned identity in relation to the changing social, natural and objective surroundings (Giddens, 1991). All together these are the fundamental features/pillars of one's self. Subjects are aiming to have coherent and consistent routinized ideas and praxes about these ontological aspects in order to feel safe in various interactions. All the contingencies of late modernity are challenging these identity fundaments, and it depends on the individuals' reflexivity and critical agency if they can emancipate themselves through these "trials" (Giddens, 1999).

Giddens (1991) distinguishes between three forms of knowledge. The subconscious, embracing the aforementioned routinized ideas and praxes, aims to make the subject's identity coherent and consistent. Practical knowledge is applied in subjective and intersubjective interactions where individuals need to adapt their routines to exact situations. These are the daily "trials" that test the applicability of subconscious knowledge. Finally, the reflexive form is the one that has gained much relevancy in late modernity, insofar as due to the different abstraction processes all kinds of references are fading away, contingencies are pervading, and subjects often have to face with the pressuring experience that their routinized ideas and praxes are dysfunctional, inadequate and nonapplicable. Merely practical knowledge is not enough in these situations as it is 
about how to use and not about how to deconstruct and reconstruct routines. Without reflexive capacities and critical agency individuals could repeatedly feel paralyzed in diverse subjective and intersubjective interactions, the experiences of which easily make them anxious. If ontological security is being destabilized because of these negative impacts, then subjects could give up the struggle for emancipation, and stick themselves to some traditional logics and semantics.

Although subjects are left alone to develop this reflexive knowledge, the constellation of which has generative impacts on individualization, this does not necessarily lead to social atomization and disintegration, or reconstruction of unequivocal references, as Giddens (1990) argues. Based on his structuration theorem, subjects are not existentially contrasted to their objective, natural and social surroundings, but they are fully embedded into them in a pan-relational sense, therefore actors and institutions are mutually shaping and reshaping each other (Giddens, 1984). Reflexivity, thus, has an individual and an institutional side as well. The structures only exist in the subjects' ideas and praxes. If the actors are able to develop a reflexive stance and critical agency, then institutions will evolve along these revised and refined perceptions, interpretations and practices. Individualization should be understood through this lens as an expansion of freedom, autonomy and subjectivity, a growing competency of political actorness, while institutions are in a continuous redesigning process in order to reflect on these social tendencies (Giddens, 1991). Agency and structures are not struggling with each other in late modernity but are contributing to a common reflexive turn that supports emancipation.

In light of the above-elaborated argument, it is important to note that subconscious and practical knowledge are related to pre-intentionality, i.e., to the construction and application of routinized ideas and praxes. Reflexive knowledge, however, is cumulating at the intentional level; subjects intentionally develop reflexive capacities and critical agency through the so-called "trials". And if the subjects could deal with these contingent subjective and intersubjective interactions which challenge their routines, then a post-intentional level reflection of institutions could contribute to their emancipation by further dismantling the traditional logics and semantics that frame individual freedom, autonomy and subjectivity. Accordingly, these are the three levels of intentionality in Giddens' theorem. In the following, the paper focuses on the latter level, i.e., on the institutional reflections as the project of 'Europe' could be reinterpreted through this lens. 


\section{Reflexive Europe}

As it was said above, religion in pre-modern era and secularized national ethos later in the classic modern period served as a source for traditional logics and semantics. The abstraction processes of late modernity are continuously challenging these particularized (religious and/or national) perspectives through universalism. Local structures are dismantling due to the abstraction of institutions, which trend also undermines the reference value of particular cultures rooted in the very same local constellations (Beck, Bonss \& Lau, 2003). The integration of Europe could be understood as an outgrowth of these tendencies, yet neither supra-nationalism, i.e., the institutional evolution of European-level superstructures leading towards a post-Westphalian arena, nor intergovernmentalism, i.e., the multi-level governance of multi-sector and multiactor partnerships establishing multilateral networks is really what late modernity embraces. An integration based on the former concept could be regressed into a power-struggle among the member states about designing and setting up the 'European' superstructure, while the latter theoretical stance explicitly aims to preserve certain privileges for all nations even if it accepts the advancement of multilateralism. Therefore, the post-intentional level institutional reflexivity of the late modern era is not an inherent element of these perspectives, which means that none of them necessarily supports the dismantlement of traditional logics and semantics. Giddens' theorem is neither about a post-national shift nor about a multi-dimensional convergence of local, regional, national, and supranational institution-reconfigurations. The aforementioned abstraction processes pervading subjective and intersubjective interactions are deeply undermining the 'either/or' dualities of both national/post-national and subnational/national/supranational framings (Beck \& Grande, 2007). Hence, this shift is rather about questioning the exclusionist, self/in-group-other/out-group distantiations in order to support the individuals' reflexive and critical ontologies (values), epistemologies (normative-cognitive ideas), and methodologies (praxes) underpinned by the 'both/and' pan-relational principle of existential interrelatedness. Reflexive Europe is not constituted along alienating/reifying distantiations, but by the emancipatory actorness of showing recognition, mutuality, and togetherness. The abstraction processes are pressuring both subjects and their institutional environment to react reflexively without relying on particular references, which is possible just through an undefined, infinite, via critical deliberations always reviewable universalism respects human oneness in the pluralism of dissimilar individual subjectivities (Beck, 2006). Therefore, by continuously developing 
and courageously applying their reflexive knowledge and critical agency, subjects have to constitute multiple identities for themselves without being stuck in one static, spatially (and temporarily) framed structural constellation. This individual actorness will be reflected by a similar institutional reflexivity leaves the pathological mechanism of distantiations behind. Only the interlinked realm of these multiple identities and reflexive institutions could enable subjects to feel ontologically safe in the contingent subjective and intersubjective interactions of late modernity.

Thus, reflexive Europe should not be understood as a revolutionary reform that restructures everything from bottom to top (or the other way around) in order to achieve a fully harmonized institutional context. On the contrary, it is rather a "meta-change" of fluid side-effects that reflexively evolves according to the interrelationships between individual actorness and institutional capacities (Beck \& Grande, 2007). It is a post-intentional level evolution of institutional shifts facilitated by the subjects' reflexive knowledge, which is developed and applied intentionally to cope with the unavoidable contingencies of late modernity. Therefore, reflexive Europe supports individuals to be able to ignore traditional logics and semantics, to constitute multiple identities without relying on onedimensional references of distantiations, and to interact based upon reflexively constructed ideas and praxes (Rumford, 2007; 2008). Both a power-concentration at the supranational level, i.e., a fastened and extended federalism aiming for a European super-state, and a reclaim of sovereignty for the member states (or subnational entities) based on nationalist sentiments, protectionist policies and isolationist visions are pathological tendencies against institutional reflexivity.

In line with this, Reflexive Europe as an entity aims to tear down all the "borders" and "barriers" that try to control various tangible and intangible flows. It is principally for the mobility of people, ideas, common causes, capitals, products, innovations, services, etc. (Delanty, 2016). It realizes that much of the contingencies of our late modern era are risks only from the perspective of traditional logics and semantics, while the rest could probably be better tackled through cosmopolitan actorness that respects universalism (Delanty \& Rumford, 2005). Therefore, the reflexive institutional shifts of Europe are striving for "futureoriented" kinds of reforms rather than appreciating "past-minded" nostalgias. It explicitly urges the diffusion of late modern uncertainties as the better the subjects can deal with these contingencies reflexively and critically, the more they are able to reestablish their ontological security. Particular cultures and their traditional patterns cannot calm individuals' anxieties down any longer, since the 
parallel globalization/localization of flows are unstoppable and non-reversible. Accordingly, the (re)stabilization of the shaken local structures is only achievable by the advancement of structural universalism (institutional abstractions) and cultural universalism (cosmopolitanism). This should not be seen as a triumph of some hegemonic trends. The 'both/and' principle rather strives for individual and institutional multilayeredness exactly how Walzer (2019) distinguishes between 'thin' and 'thick' morality: recognizing and embracing human 'similarities' in order to be able to respect human 'dissimilarities'.

As it was mentioned above, Reflexive Europe urges individual subjects to develop their reflexive and critical capacities. It expects both political and more general public (civic) engagement from the people. The most serious threat against Reflexive Europe is if the agents are keeping distance from its institutions, if there are growing tendencies of distrust, democratic deficit, social dissatisfactions, i.e. disengagement (Beck \& Grande, 2007). Subjects have to develop and apply their reflexive and critical capacities in late modernity, otherwise they would experience hardships in their everyday subjective and intersubjective interactions. Yet, these individual efforts are also generative impulses for the reflexive institutional reflections that Europe should be all about. Hence, if agents are rather disengaging from political and public processes, and they choose the path of isolation and atomization, as well as the praxes of distantiation, then their individual emancipation will struggle, while Reflexive Europe as a project will also fail with all its integrative potentials. Accordingly, engagement is a key factor and also a pre-condition for free flows and social mobility. In order to facilitate engagement, Reflexive Europe has to strive for political transparency, public accountability, and civic participation/involvement. It rejects all kinds of ideological hegemonies as well as discourses based on idea-impositions without options for deliberation and contestation. Restrictive regulatory framings are outcomes of biased, scaremongering discourses, therefore the moral criterion of "every subjective ideational construction is valid, as long as it does not aim to foreclose another one from the deliberative communication of truth-candidates" is a core pillar for Reflexive Europe (Rorty, 1991). The 'both/and' principle refuses the discursive application of ideas based on Truths and favors, instead, the narrative construction of subjective perceptions and interpretations aim for collectively acceptable and useful, ever revisable pragmatic justices. Broad political and public (civic) engagement is only achievable based on justiceoriented communicative actions.

For this reflexive institutional shift, four basic fields of socialization should be 
restructured in the late modern Europe. These are education, labor, science, and art. Education is being redesigned according to the model of life-long-learning (LLL), which is dedicated to contribute to the subjects' efforts for reflexive and critical agency (Boros, 2011). Hence, LLL encourages individuals, irrespective of their age, to gain new skills and competencies; to critically review their ideas (cognitions) and enrich them through diverse perspectives; to be interested in new professions; to take new challenges; and to build up new career-paths. LLL supports subjects to be multi-layered in a sense that their identities are up to self-initiated de- and reconstructions without traumas or serious life-junctures. It encourages individuals to understand their subjectivity as an infinitely autonomous actorness. Of course, the institutional structure of education has to be changed for these objectives already from primary level. Teachers, instructors, professors, etc. are not "authorities" but mentors in this new framework; courses are focusing more on the development of skills and practical competencies than providing lexical knowledge; lecture-style is not frontal and competitive-oriented arranged into thematic lessons, but cooperative and problem-oriented organized into projects and working partnerships; curriculum is structured according to the logic of general basics and individual specialization, instead of striving for high standards in many fields without subjective preferences. Therefore, education in late modernity is still a crucial institutional agent of coaching, yet not any longer in a sense of creating uniformity based on traditional references, but rather facilitating individualization, i.e., respected subjective pluralisms. It encourages the subjects to develop a critical and reflexive stance, as well as to apply communicative actions based on deliberation and contestation. Late modern education rejects Truths; it strives, instead, for pragmatic, useful, and revisable justices; it questions the logic of rationalization traced back to binary codes (true/false) and 'objective' judgments, and replaces these alienating/reifying semantics with emotionally-driven and individually perceived/interpreted pluralistic subjectivities. Therefore, this completely redesigned education of the late modern Europe is not about 'socialization' (be one of us), but about 'encouragement' (be yourself).

The structure of labor is changing in the same fashion. The hierarchically ordered, vertically segmented positions and competencies are becoming meaningless. Mega-conglomerates that once provided 'status', 'role', 'identity', and 'community-attachment' to the workers in exchange for their loyalty to the firm are rapidly dissolving, and giving place to horizontally organized, network-arranged partnerships among cell-like, adaptive, flexible, and mobile co-work groups focusing on boom-kinds-of-projects instead of long-term, 
gradually evolving programs (Boltanski \& Chiapello, 2005). The market requires competitiveness, the demand for which is sustainably achievable just by innovations. Yet, to encourage workers' (agents') innovativeness, rigid structural framings, superior-inferior statuses, as well as unequivocal patterns and references all have to be considerably eased as these constraints heavily hamper subjectivity. Innovative approaches are rooted in reflexivity and critical revisions; subjects have to question and revise the applied solutions, explanations, understandings, and interpretations. More innovativeness means more readiness for changing things in order to make life better (i.e., more effective mapping, registering, and administering of diverse "problems", improved planning, strategies, and solutions, more comprehensive and more in-depth changes and reforms). Therefore, reflexive and critical actorness cannot be reduced to contributions to productivity. Workers are becoming subjective agents who produce, beyond the commodities, also their cognitive-normative ideas, their desires and necessities, as well as their living conditions and institutional framings (Kapitány \& Kapitány, 2013). Accordingly, in late modernity, the competitiveness- and innovativenessoriented labor starts to undermine the whole structure of classic capitalism (Lash \& Urry, 1987). What was once ordered along the alienated and reified logic of maximizing gains and minimizing losses is starting to be reflexively and critically revised by creative and unique agents who are more and more aware of the constellation that "producing" is also about "constituting"; both the self and its objective, natural and social surroundings. So, Reflexive Europe secures special grants for innovative projects, among them socially innovative initiations that involve a broad pool of stakeholders and consumers; it supports state-of-the-art SMEs and start-ups both financially and institutionally; it encourages workers' mobility and nomadic lifestyle by easing regulative restrictions, dismantling labor-related quotas, proposing cheap loans for the re-training periods, and providing LLL kinds of professional and language courses.

Finally, the shifting role of science and art should be discussed as well. Both respective to education and labor, the argument emphasized the trend of growing reflexive and critical agency, i.e., the unfolding autonomous subjectivity. Self-constitution is a continuous act of autopoietic (narrative and performative) identity de- and reconstruction. Revising individual perceptions and interpretations, subjectively formulated cognitive-normative ideas means comprehensive and deep conceptualizing. Therefore, in late modernity all people are frequently excersing their "intellectual" and "aesthetic" agency. They are becoming "intellectuals" and "artists" (Beck \& Grande, 2007). Reflexive Europe has important emancipatory potentials about these prospects in the fields of 
science and art. It pushes both sectors to deepen and strengthen their social embeddedness, to share competencies with individual ("lay") actors and to actively involve them. This shift has impacts of 'democratization' and 'decentral ization'/'deperipherization' on science and art (Boros, 2011). The former means that professionals of these sectors become "mediators" who are contributing to the individual agents' intellectual and aesthetic communicative interactions by impulsive concepts (ideas), constructivism-based critical approaches, as well as deliberative and consensus-oriented discursive methods (Beck, 2005). Decentralization and deperipherization on the other hand refer to the tendency that hegemonic ideational contents as mainstream explanations (paradigms) are continuously and intentionally challenged by marginalized cognitive-normative epistemologies in order to remove the previous ones from the center, while the latter ideas from the periphery. In late modernity all intellectual and aesthetic approaches are equal, none of them are considered as more reflective, since it is not Truth that matters but deliberative justification among mutually recognized Truth-candidates (Rorty, 1991). Those who try to exclude others from this collective actorness of creating consensual justice, either by Truth-vindication or idea-imposition, they are actually excluding themselves from the communicative interactions. Thus, scientists and artists still have the function of "gate-keeping" in late modernity, yet not in a sense of searching and proclaiming Truths, but facilitating justice (Lash, 1999).

\section{References}

Balibar,E.(2003), We, the PeopleofEurope?Reflectionson TransnationalCitizenship, Princeton: Princeton University Press. https://doi.org/10.1177/0263276403020002001

Beck, U. (1992), Risk Society: Towards a New Modernity, London: Sage.

Beck, U. (1998), World Risk Society, Cambridge: Polity Press.

Beck, U. (1999), What Is Globalization? Cambridge: Polity Press.

Beck, U. (2005), Power in the Global Age, Cambridge: Polity Press.

Beck, U. (2006), Cosmopolitan Vision, Cambridge: Polity Press.

Beck, U. \& Beck-Gernsheim, E. (1995), The Normal Chaos of Love, Cambridge: Polity Press.

Beck, U. \& Beck-Gernsheim, E. (2002), Individualization: Institutionalized Individualism and its Social and Political Consequences, London: Sage.

Beck, U.; Bonss, W. \& Lau, C. (2003), 'The Theory of Reflexive Modernisation,' Theory and Society, vol. 32, no. 2, pp. 1-33. 
Beck, U.; Giddens, A. \& Lash, S. (1994), Reflexive Modernization. Politics, Tradition and Aesthetics in the Modern Social Order, Cambridge: Polity Press.

Beck, U. \& Grande, E. (2007), Cosmopolitan Europe, Cambridge: Polity Press.

Boltanski, L. \& Chiapello, É. (2005), New Spirit of Capitalism, London: Verso.

Boros, J. (2011), Demokrácia és szabadság [Democracy and freedom], Veszprém: Iskolakultúra.

Delanty, G. (2003), 'Conceptions of Europe: a review of recent trends,' European Journal of Social Theory, vol. 6, no. 4, pp. 471-488. https://doi.org/10.1177/13684310030064001

Delanty, G. (2016), 'Multiple Europes, multiple modernities: conceptualising the plurality of Europe,' Comparative European Politics, vol. 13, no. 4, pp. 398-416. https://doi.org/10.1057/cep.2015.33

Delanty, G. \& Rumford, C. (2005), Rethinking Europe: Social Theory and the Implications of Europeanization, Abingdon, New York: Routledge.

Giddens, A. (1984), The Constitution of Society. Outline of the Theory of Structuration, Cambridge: Polity.

Giddens, A. (1990), The Consequences of Modernity, Cambridge: Polity.

Giddens, A. (1991), Modernity and Self-Identity. Self and Society in the Late Modern Age, Cambridge: Polity.

Giddens, A. (1992), The Transformation of Intimacy: Sexuality, Love and Eroticism in Modern Societies, Cambridge: Polity.

Giddens, A. (1995), Politics, Sociology and Social Theory: Encounters with Classical and Contemporary Social Thought, Cambridge: Polity.

Giddens, A. (1999), Runaway World: How Globalization is Reshaping Our Lives, London: Profile.

Habermas, J. (2009), Europe. The Faltering Project, London: Polity.

Kapitány, Á. \& Kapitány, G. (2013), Szellemi termelési mód [Intellectual mode of production], Budapest: Kossuth.

Lash, S. (1999), Another Modernity. A Different Rationality, Oxford: Blackwell.

Lash, S. \& Urry, J. (1987), The End of Organized Capitalism, Cambridge: Polity Books.

Rorty, R. (1991), Objectivity, Relativism and Truth: Philosophical Papers I., Cambridge: Cambridge University Press. https://doi.org/10.1017/CBO9781139173643

Rumford, C. (2007), Cosmopolitanism and Europe, Liverpool: Liverpool University Press.

Rumford, C. (2008), Cosmopolitan Spaces: Europe, Globalization, Theory, Abingdon: Routledge. https://doi.org/10.4324/9780203891438 
Zoltán Grünhut, PhD, is a research fellow at the Centre for Economic and Regional Studies. He has a background in political science. He did post-doc researches at the Israeli Democracy Institute (Jerusalem) and at the Middle East Technical University (Ankara). His researches are focusing on cultural similarities and dissimilarities, social trust, individual emancipation and institutional reflexivity, European integration. 